\title{
A rapid method for the extraction of whole cell proteins from Candida species
}

\author{
Nada Al-Rawi, Kevin Kavanagh* \\ Medical Mycology Unit, Department of Biology, National University of Ireland, Maynooth, Co. Kildare, Ireland \\ Received 11 May 1998; received in revised form 30 July 1998; accepted 10 August 1998
}

\begin{abstract}
A rapid method for the extraction of whole cell proteins from yeasts of the genus Candida has been developed. Stationary phase cells $\left(10^{9}\right)$ were harvested, washed with phosphate-buffered saline and resuspended in $200 \mu l$ of sodium dodecyl sulphate (SDS) sample buffer. The cell suspension was boiled for $20 \mathrm{~min}$ and $20 \mu \mathrm{l}$ were applied directly to a $12.5 \%$ polyacrylamide gel. Electrophoresis was performed for $18 \mathrm{~h}$ at $75 \mathrm{~V}$, after which time, staining with Coomassie Brilliant Blue R 250 revealed the presence of approximately 30 distinct bands, depending upon the species. This method of extracting whole cell proteins is rapid, easy to perform and has been used with a range of Candida species (viz. C. albicans, C. tropicalis, C. pseudotropicalis, C. parapsilosis, C. lusitaniae, C. krusei and C. glabrata) obtained from both laboratory stocks and clinical samples. It enables the differentiation of a large number of Candida species based upon the protein banding pattern(s) obtained after SDS-polyacrylamide gel electrophoretic analysis. (c) 1998 Elsevier Science B.V. All rights reserved.
\end{abstract}

Keywords: Candida; SDS-PAGE; Whole cell protein

\section{Introduction}

Candida albicans is an opportunistic fungal pathogen that is the principal cause of superficial and systemic candidiasis (Cutler, 1991). Cases of superficial candidiasis [oral candidiasis, vulvovaginal candidiasis (VVC)] are relatively common whereas systemic candidiasis occurs infrequently, mainly in severely immunocompromised patients and can prove fatal. VVC affects approximately $75 \%$ of women at some point and is caused predominantly, although not exclusively, by C. albicans. Other Candida species that have been implicated in this

\footnotetext{
${ }^{*}$ Corresponding author. Tel.: + 353-1-708-3859; fax: + 353-1708-3845; e-mail: kevin.kavanagh@may.ie
}

condition include Candida glabrata (Redondo-Lopez et al., 1990) and Candida tropicalis (Geiger, 1995). Recurrent vulvovaginal candidiasis (RVVC) affects approximately $5 \%$ of women and the factors responsible for its' persistence are poorly characterised (Odds, 1993). In many instances of VVC and RVVC, more than one species of yeast may be responsible for infection, so a rapid method for differentiating Candida species is required (Odds, 1993).

Several methods have been developed for the identification and differentiation of Candida species. Morphotyping (Phongpaichit et al., 1987), resistogram typing (McCreight and Warnock, 1982), karyotyping (Schwartz and Cantor, 1984), restriction endonuclease analysis of genomic DNA (Vazquez et 
al., 1993) and polymerase chain reaction (PCR) (Haynes et al., 1995) have been widely used in recent years for the identification of yeasts. Sodium dodecyl sulphate-polyacrylamide gel electrophoresis (SDS-PAGE) has been employed to analyse the constituents of soluble extracts obtained from intact cells and isolated cell walls. Extraction methods have included treatment of cells or isolated cell walls with $\beta$-mercaptoethanol and SDS (Chaffin and Stocco, 1983) or using combinations of dithiothreitol, protease, lyticase and chitinase (Ponton and Jones, 1986). Rupture of cells by agitation with glass beads or sonication has allowed the extraction of proteins from C. albicans and Saccharomyces cerevisiae, however, these methods are time-consuming and require specialized equipment (Catley, 1990). While a number of methods exist for the extraction of proteins from yeast cells, the method employed can affect both the composition and size of moieties present in the extract (Casanova and Chaffin, 1991).

Whole cell protein profiles obtained by SDSPAGE may be labelled radioactively or with stains such as Coomassie Brilliant Blue and have been used for the differentiation of yeast species (Vancanneyt et al., 1991). Horvath and Riezman (1994) developed and evaluated a rapid method for the extraction of proteins from $S$. cerevisiae for SDS-PAGE and Western blotting. This extraction procedure has the advantage of being rapid and easy to perform and could be used for the routine identification and differentiation of a large number of yeast strains, although it was not equally applicable to all yeasts tested.

A modification of the method of Horvath and Riezman (1994) for the rapid extraction of whole cell proteins from a number of Candida species is presented here. These could subsequently be analysed by SDS-PAGE to allow the identification and differentiation of clinically important species.

\section{Materials and methods}

\subsection{Yeast cultures}

The following yeasts were used for the extraction of whole cell proteins: C. albicans 10231 and 44990 were obtained from the American Type Culture
Collection, Rockville, MD, USA. C. tropicalis 3097 and 3109, Candida pseudotropicalis 3106 and 3234, Candida parapsilosis 3207 and 3209, Candida krusei 3100 and 3321, and C. glabrata 4733 were obtained from the National Collection of Pathogenic Fungi, London, UK.

Ten clinical yeast isolates (five C. albicans, three C. glabrata, one Candida lusitaniae and one $C$. krusei) were obtained from patients with symptoms of vaginitis. Vaginal samples were collected with sterile cotton swabs and inoculated onto CHROMagar plates (Mast Diagnostic, Bootle, UK) and incubated at $37^{\circ} \mathrm{C}$ for $48 \mathrm{~h}$. All yeast isolates observed on CHROMagar were identified by colony morphology and pigmentation (Odds and Bernaerts, 1994). Identification was confirmed using the API 20C AUX test system (Bio Merieux, Marcy L'Etoile, France) and, in the case of $C$. albicans, by the ability to form germ tubes in foetal calf serum at $37^{\circ} \mathrm{C}$ and to produce chlamydospores on corn meal agar.

\subsection{Culture conditions}

Yeast isolates were grown to the stationary phase (approximately $5 \times 10^{8} / \mathrm{ml}$ ) overnight in $50 \mathrm{ml}$ of YEPD liquid medium [2\% (w/v) glucose (Sigma, St. Louis, MO, USA), 2\% (w/v) Bactopeptone (Oxoid, Basingstoke, UK) and $1 \%(\mathrm{w} / \mathrm{v})$ Yeast Extract (Oxoid)] in $100 \mathrm{ml}$ conical flasks at $30^{\circ} \mathrm{C}$ and 200 rpm in an orbital incubator. Cultures were maintained on YEPD agar plates [as above, but solidified with the addition of $2 \%(\mathrm{w} / \mathrm{v})$ agar (Difco, Detroit, MI, USA)] at $4^{\circ} \mathrm{C}$ and were sub-cultured every four weeks.

\subsection{Whole cell protein extraction}

Stationary phase cultures were harvested by centrifugation at $2280 \mathrm{~g}$ for $5 \mathrm{~min}$ in a Beckmann GS-6 centrifuge, washed twice with phosphate-buffered saline (PBS) and $10^{9}$ cells were resuspended in 200 $\mu l$ of sample buffer [0.06 M Tris- $\mathrm{HCl}, \mathrm{pH} 6.8,2 \%$ $(\mathrm{w} / \mathrm{v}) \operatorname{SDS}$ (Sigma), 5\% (v/v) $\beta$-mercaptoethanol, $10 \%$ (v/v) glycerol, $1 \mathrm{mM}$ phenylmethylsulfonylfluoride (Sigma) and 0.5\% (w/v) bromophenol blue (Sigma)]. The suspensions were boiled for 20 min and $20 \mu \mathrm{l}$ were applied directly to each well of a $12.5 \%(\mathrm{w} / \mathrm{v})$ polyacrylamide gel. 


\subsection{SDS-PAGE}

One-dimensional SDS-PAGE was performed using a modification of the technique of Hames (1990). Samples were loaded onto a $12.5 \%(\mathrm{w} / \mathrm{v})$ polyacrylamide gel in a discontinuous buffer system and subjected to electrophoresis at $75 \mathrm{~V}$ for $18 \mathrm{~h}$. The reservoir buffer consisted of $0.25 \mathrm{M}$ Tris- $\mathrm{HCl}$, $1.92 \mathrm{M}$ glycine (Sigma) and 1\% (w/v) SDS (pH 8.3). The gel was stained with $0.05 \%(\mathrm{w} / \mathrm{v})$ Coomassie Brilliant Blue R 250 (Sigma) for $4 \mathrm{~h}$ and destained in $10 \%(\mathrm{v} / \mathrm{v})$ acetic acid and $20 \%(\mathrm{v} / \mathrm{v})$ methanol.

Protein standards used for estimation of molecular weight were: bovine albumin, 66,000 Da; egg albumin, 45,000 Da; glyceraldehyde-3-phosphate dehydrogenase, 36,000 Da; bovine carbonic anhydrase, 29,000 Da; bovine pancreas trypsinogen, 24,000 Da; soybean trypsin inhibitor, 20,000 Da and bovine milk $\alpha$-lactalbumin, 14,200 Da (Sigma).

\section{Results}

A rapid method for the extraction of proteins from S. cerevisiae was developed by Horvath and Riezman (1994). This involved the suspension of approximately $5 \times 10^{7}$ exponential phase cells in $100 \mu$ of SDS sample buffer, heating to $95^{\circ} \mathrm{C}$ for $5 \mathrm{~min}$ and clarification of the sample by centrifugation at $14,000 \mathrm{~g}$ for $5 \mathrm{~min}$. Samples $(30-50 \mu \mathrm{l})$ of the supernatant were then applied to a SDS gel and analysed by PAGE. Application of this technique to C. albicans gave very poor results. Increasing the sample cell number from $5 \times 10^{7}$ to $1 \times 10^{9}$ failed to yield sufficient protein to produce a well-defined protein profile using this method, so a number of variations were attempted in order to develop a method that would retain the rapidity and ease of use of the method of Horvath and Riezman (1994) but increase its applicability to a range of Candida species.

C. albicans 10231, 44990 and five C. albicans isolates obtained from clinical samples were grown to the stationary phase in YEPD medium overnight, harvested by centrifugation, washed with PBS and $1 \times 10^{9}$ cells were resuspended in $200 \mu \mathrm{l}$ of SDS sample buffer and boiled for $20 \mathrm{~min}$. A sample (20 $\mu \mathrm{l})$ of this cell suspension was subsequently applied directly to a $12.5 \%$ polyacrylamide gel as described. SDS-PAGE analysis revealed the presence of approximately 30 distinct protein bands with molecular weights ranging in size from 63,000 to $12,000 \mathrm{Da}$ (Fig. 1). The protein banding patterns of the five $C$. albicans clinical isolates were identical to those of $C$. albicans 10231 and 44990 (Fig. 1) and distinct from those of other Candida species (Fig. 2 Fig. 3 Fig. 4).

The applicability of this technique to a range of Candida species was established by extracting whole cell proteins from stationary phase cells of $C$. glabrata 4733 and the three C. glabrata clinical isolates. The extraction procedure involved harvesting $10^{9}$ cells and boiling them in SDS sample buffer

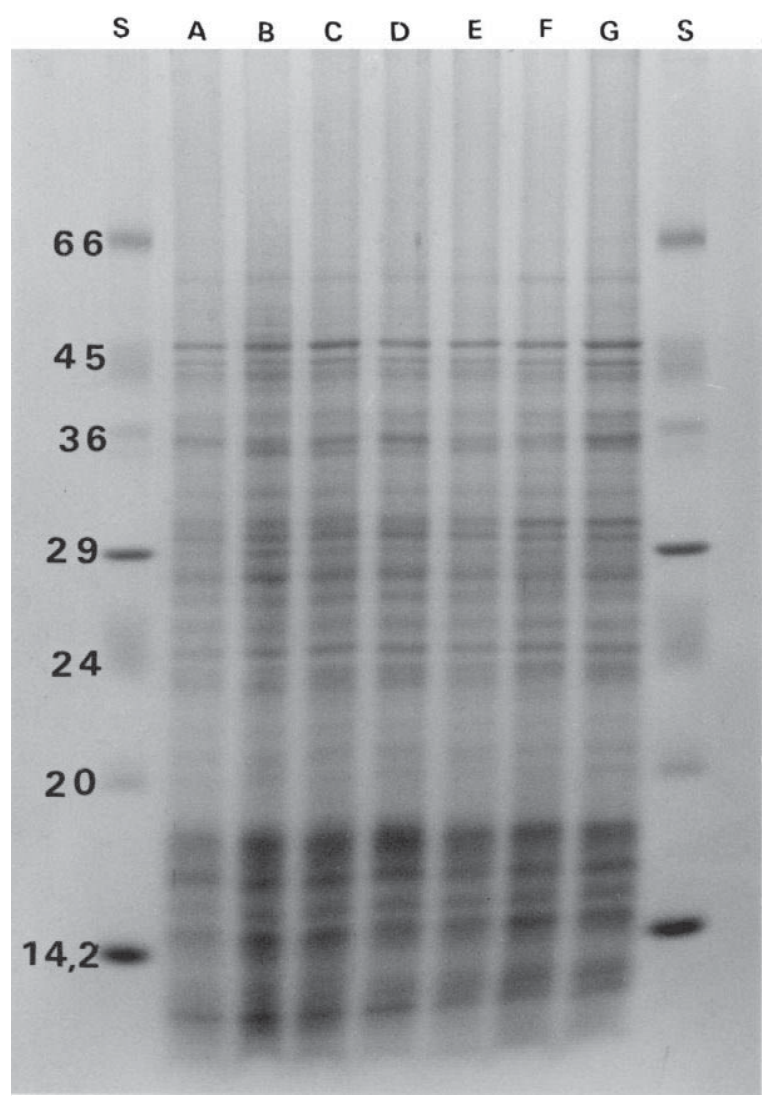

Fig. 1. Protein banding patterns of Candida albicans isolates. Proteins were extracted as described from seven $C$. albicans isolates and analysed by SDS-PAGE. The following isolates were used: C. albicans 10231 (lane A), C. albicans 44990 (lane B) and C. albicans clinical isolates (lanes $\mathrm{C}-\mathrm{G}$ ). The migration of the molecular weight standards is shown in lane $S\left(M_{r} \times 10^{-3}\right)$. 


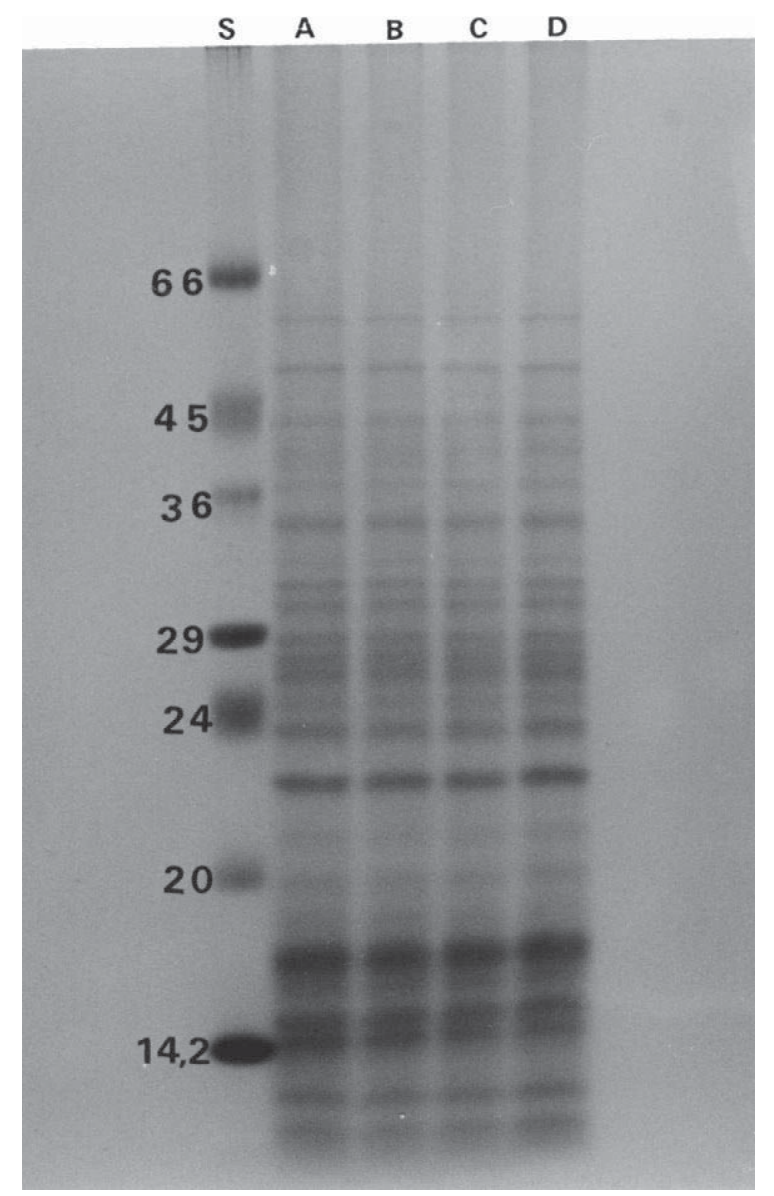

Fig. 2. Protein profiles of Candida glabrata isolates. Whole cell proteins were extracted from C. glabrata 4733 (lane A) and three C. glabrata clinical isolates (lanes $\mathrm{B}-\mathrm{D}$ ) as described. The molecular weight standards are present in lane $S\left(M_{r} \times 10^{-3}\right)$.

for 20 min prior to loading onto a $12.5 \%$ polyacrylamide gel. The gel showed a high degree of similarity between the protein banding patterns of the four C. glabrata isolates (Fig. 2), but the banding patterns were distinct from those of the C. albicans isolates (Fig. 1) and the other Candida species (Figs. 3 and 4).

This method of whole cell protein extraction was also used to distinguish between the four Candida species obtained from clinical specimens. Proteins were extracted as described. SDS-PAGE revealed the clearly distinguishable protein banding patterns of the different clinical isolates (Fig. 3). Whole cell proteins were also extracted using this method from

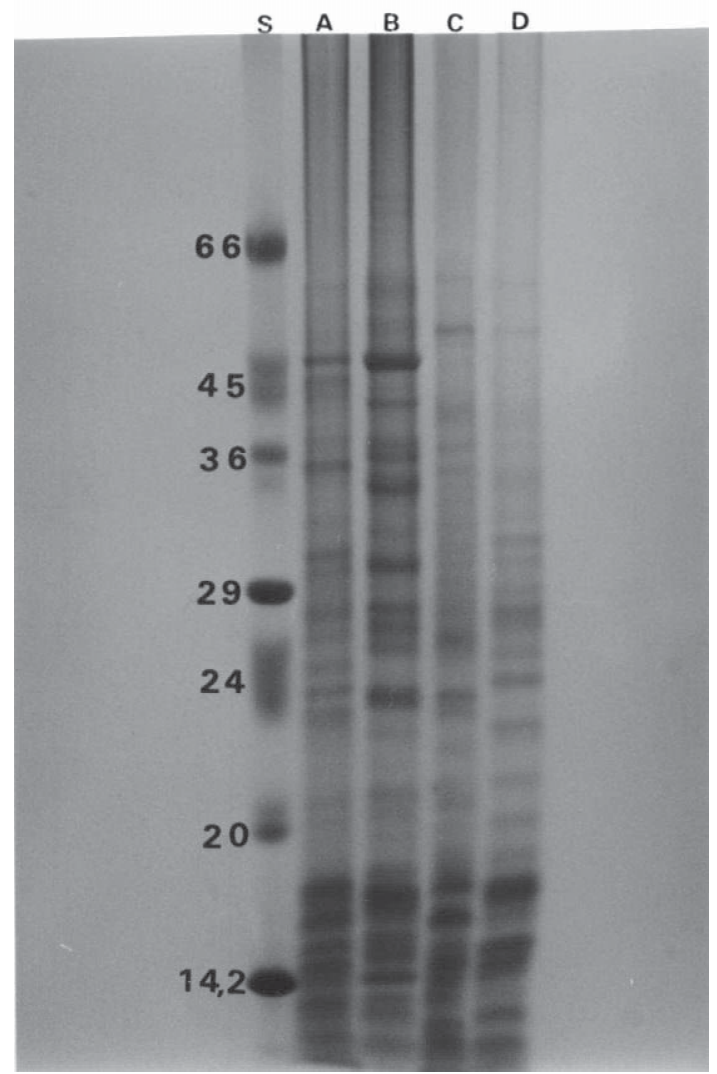

Fig. 3. Protein profiles of clinical isolates of Candida species. Proteins were extracted as described and analysed by SDS-PAGE. The following clinical isolates were used: C. albicans (lane A), C. lusitaniae (lane B), C. krusei (lane C) and C. glabrata (lane D). The molecular weight standards are in lane $S\left(M_{r} \times 10^{-3}\right)$.

two isolates each of $C$. albicans, C. tropicalis, $C$. parapsilosis, C. pseudotropicalis and C. krusei and, again, there are clear differences between the protein banding patterns obtained after SDS-PAGE of each species and a high degree of similarity between those profiles obtained from the same species (Fig. 4).

\section{Discussion}

Polyacrylamide gel electrophoresis plays a major role in the experimental analysis of proteins and protein mixtures. One-dimensional polyacrylamide gel electrophoresis is still the most widespread form of the technique (Hames, 1990) and has been used to separate proteins from cell extracts after treatment 


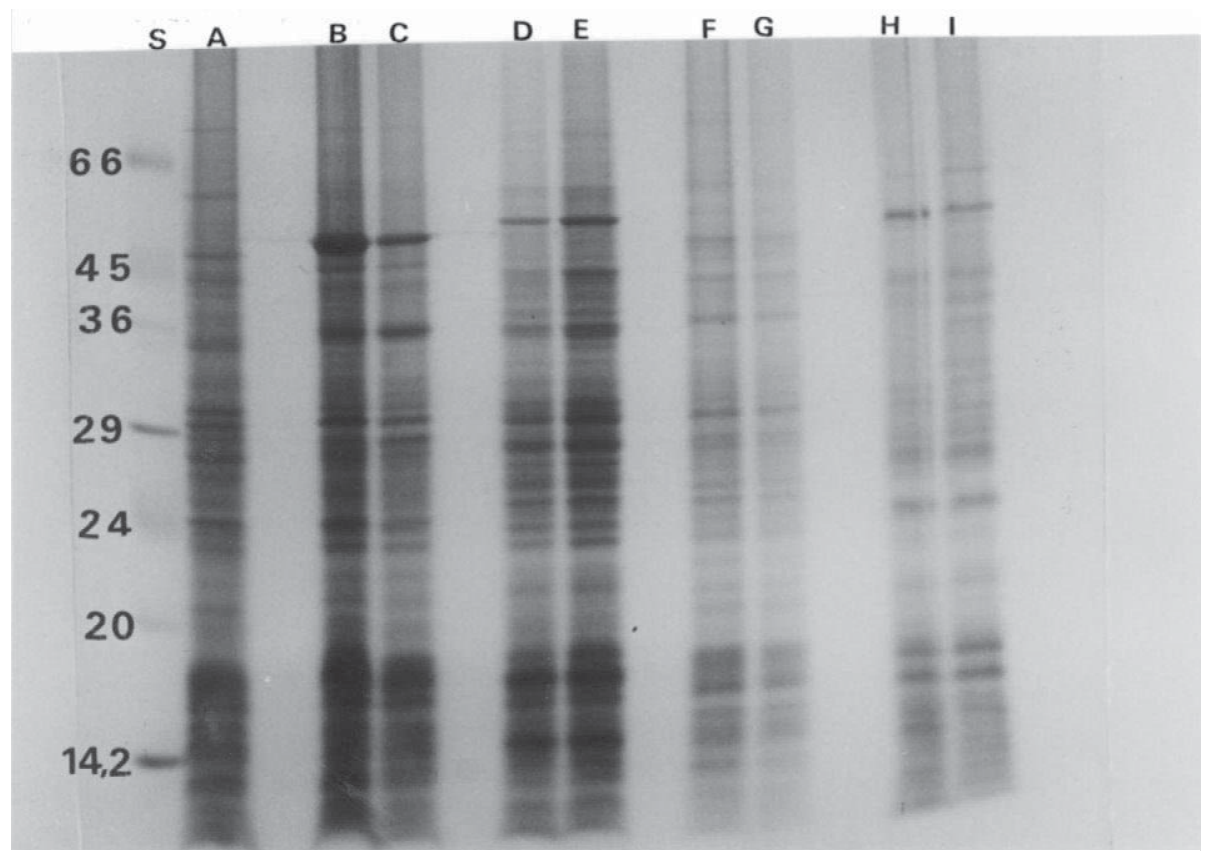

Fig. 4. Protein profiles of Candida species. C. albicans 10231 (lane A), C. tropicalis 3097 and 3109 (lanes B and C, respectively), C. parapsilosis 3106 and 3234 (lanes D and E), C. pseudotropicalis 3207 and 3209 (lanes F and G) and C. krusei 3100 and 3321 (lanes H and I). The migration of the molecular weight standards is shown in lane $S\left(M_{r} \times 10^{-3}\right)$.

with SDS and $\beta$-mercaptoethanol. Protein bands can be visualized radioactively or by staining with Coomassie Brilliant Blue and protein profiles from different yeast species can be compared in order to facilitate identification (Vancanneyt et al., 1991).

In this study, a simple method for the extraction of whole cell proteins from a range of Candida species has been developed. The basic differences between this method and that described by Horvath and Riezman (1994) for S. cerevisiae is that, after boiling stationary phase cells (rather than exponential phase cells) in SDS sample buffer for 20 min (rather than 5 min), $20 \mu \mathrm{l}$ of cell suspension (rather than the supernatant) are applied directly to the polyacrylamide gel. This facilitates the production of a well-defined protein banding pattern, which can be used to identify and differentiate Candida species. In contrast, loading $20 \mu \mathrm{l}$ of SDS sample buffer containing cell supernatant failed to give a protein banding pattern. Boiling in SDS sample buffer is insufficient to release enough protein from cells to allow the production of a distinct banding pattern after SDS-PAGE. It appears that the majority of proteins are extracted from the cells during electrophoresis. The more rigorous extraction procedure required to obtain proteins from Candida species may be partly explained by the presence of the strong, multi-layered cell wall retarding cell lysis (Cassone, 1989).

It has been demonstrated here that the protein banding patterns of C. albicans 10231 and 44990 are identical to those of five $C$. albicans isolates obtained from women with symptoms of VVC and distinct from the banding patterns of a number of $C$. glabrata isolates (Fig. 2). Similarly, the banding patterns of laboratory isolates and clinical isolates of C. glabrata show a high degree of homology. When samples of a number of different Candida species are run on the same gel, clear differences that aid species differentiation are visible (Figs. 3 and 4).

This modification of the method of Horvath and Riezman (1994) allows the rapid extraction of proteins from a range of Candida species. The procedure is faster and less labour intensive than methods that depend upon the extraction of proteins from cells by agitation with glass beads or by 
sonication and it gives sufficient protein from $10^{9}$ stationary phase cells to allow the production of well-defined protein profiles by SDS-PAGE. This method enables the identification and differentiation of Candida species from clinical samples by comparing the profiles with those of known Candida species from culture stocks. Using this method, whole cell proteins can be extracted from between ten and 15 stationary phase yeast cultures, separated by SDSPAGE and the proteins can be visualized by staining. While other methods of yeast identification are faster (e.g. PCR-based techniques), the method described here is less labour intensive than conventional methods of protein extraction and offers the possibility of examining a large number of isolates simultaneously.

\section{Acknowledgements}

The authors are grateful to Dr. Derek Freedman for supplying clinical samples.

\section{References}

Casanova, M., Chaffin, W.L., 1991. Cell wall glycoproteins of Candida albicans as released by different methods. J. Gen. Microbiol. 137, 1045-1051.

Cassone, A., 1989. Cell wall of Candida albicans: Its functions and its impact on the host. Curr. Top. Mycol. 3, 248-314.

Catley, B., 1990. Isolation and analysis of cell walls. In: Campbell, I., Duffus, J. (Eds.), Yeast: A Practical Approach. IRL Press, Oxford, pp. 163-183.

Chaffin, W.L., Stocco, D.M., 1983. Cell wall proteins of Candida albicans. Can. J. Microbiol. 29, 1438-1444.

Cutler, J.E., 1991. Putative virulence factors of Candida albicans . Ann. Rev. Microbiol. 45, 187-218.
Geiger, A., 1995. The epidemiology of vulvovaginal candidiasis among university students. Am. J. Pub. Health. 8, 1146-1148.

Hames, B.D., 1990. One dimensional polyacrylamide gel electrophoresis. In: Hames, B.D., Rickwood, D. (Eds.), Gel Electrophoresis of Proteins. A Practical Approach. second ed. IRL press, Oxford, pp. 1-139.

Haynes, K., Westerneng, T., Fell, J., Moens, W., 1995. Rapid detection and identification of pathogenic fungi by polymerase chain reaction amplification of large subunit ribosomal DNA. J. Med. Vet. Mycol. 33, 319-325.

Horvath, A., Riezman, H., 1994. Rapid protein extraction from Saccharomyces cerevisiae. Yeast 10, 1305-1310.

McCreight, M.C., Warnock, D.W., 1982. Enhanced differentiation of isolates of Candida albicans using a modified resistogram method. Mykosen 25, 589-598.

Odds, F.C., 1993. Vulvovaginal Candida infection: current perspectives. J. Eur. Acad. Dermatol. Venereol. 2, 174-179.

Odds, F.C., Bernaerts, R., 1994. CHROMagar Candida, a new differential isolation medium for presumptive identification of clinically important Candida species. J. Clin. Microbiol. 32, 1923-1929.

Phongpaichit, S., Mackenzie, W., Fraser, C., 1987. Strain differentiation of Candida albicans by morphotyping. Epidemol. Infect. 99, 421-428.

Ponton, J., Jones, J., 1986. Analysis of cell wall extracts of Candida albicans by sodium dodecyl sulfate polyacrylamide gel electrophoresis and western blot techniques. Infect. Immun. 53, 565-572.

Redondo-Lopez, V., Lynch, M., Schmitt, C., Cook, R., Sobel, J., 1990. Torulopsis glabrata vaginitis: clinical aspects and susceptibility to antifungal agents. Obstet. Gynecol. 76, 651-655.

Schwartz, D.C., Cantor, C.R., 1984. Separation of yeast chromosome sized DNAs by pulsed field gradient gel electrophoresis. Cell 37, 66-75.

Vancanneyt, M., Pot, B., Hennebert. G., Kebsters, K., 1991. Differentiation of yeast species based on electrophoretic wholecell protein patterns. Syst. Appl. Microbiol. 14, 23-32.

Vazquez, J.A., Sanchez, V., Dimuchowski, C., Dembry, L., Sobel, J., Zervos, M., 1993. Nosocomial acquisition of Candida albicans: An epidemiologic study. J. Infect. Dis. 168, 195-201. 